\title{
Effect of CRM's Critical Success Factors on Company Performance
}

\author{
Mübeyyen Tepe Küçükoğlu \\ Yeni Yüzyıl University, İstanbul, Turkey \\ Recep İbrahim Pınar \\ İstanbul University, İstanbul, Turkey
}

\begin{abstract}
In the last years, most of the leader companies have advantages of their CRM (customer relationship management) systems in order to improve their market share. These companies implement CRM systems to get loyal customer portfolio and maintain the sustainability of it. While they are building CRM strategies, they try to catch business excellence results like valuable marketing opportunities, improve customer value and customer satisfaction. CRM gained prominence as a marketing sub-discipline in the 1990s, fueled by publications like The One to One Future and The Loyalty Effect. Some studies were especially powerful in highlighting the gap between the cost of acquiring customers and retaining them. The quest for competitive advantage and profitability triggered a rush to implement CRM programs in enterprises both large and small in all corners of the globe. Different kinds of studies show that there are some key components which play a critical role in gaining success for companies which use CRM applications. At this situation, these key components are named as critical success factors. Purpose of this study is to find out that how these critical success factors affect results which show company performance. On this direction, critical success factors are defined as independent variable and company performance is defined as dependent variable. A supportive model is suggested. In order to verify proposed model, hypotheses are developed and a survey is applied in automotive sales agents in Turkey. The study is completed with survey results.
\end{abstract}

Keywords: company performance, critical success factors, CRM (customer relationship management)

\section{Introduction}

Zablah, Bellenger, and Johnston (2004) analyzed CRM (customer relationship management) from different perspectives for its accurate definition. CRM has plenty of definitions in the literature. When all these definitions are analyzed, five basic factors are found behind CRM definition which is process, strategy, philosophy, capability, and technological tool based definition.

CRM is a concept that enables an organization to tailor specific products or services to each individual customer. In the most advanced scenario, CRM may be used to create a personalized one-to-one experience that will give the individual customer a sense of being cared for, thus opening up new marketing opportunities

Mübeyyen Tepe Küçükoğlu, Ph.D., lecturer, Vocational School Logistics Program, Yeni Yüzyıl University, İstanbul, Turkey. Recep İbrahim Pınar, Ph.D., professor, Faculty of Business Management, İstanbul University, İstanbul, Turkey.

Correspondence concerning this article should be addressed to Mübeyyen Tepe Küçükoğlu, Vocational School Logistics Program, Yeni Yüzyıl University, Yeni Doğan Mahallesi Yılanlı Ayazma Caddesi, No 26 P.K. 34010, Cevizlibağ, Zeytinburnu, İstanbul, Turkey. E-mail: mubeyyen.tepe@yeniyuzyil.edu.tr. 
based on the preferences and history of the customer. CRM is a customer-focused business strategy that aims to increase customer satisfaction and customer loyalty by offering a more responsive and customized service to each customer (Croteau \& Li, 2003).

Most organizations have perceived the CRM concept as a technological solution for problems in individual areas, accompanied by a great deal of uncoordinated initiatives. Nevertheless, CRM must be conceived as a strategy, due to its human, technological, and processes implications, at the time an organization decides to implement it. These factors cover the three key aspects of every CRM strategy (human factor, processes, and technology), giving a global focus and propitiating success in the implementation of a CRM strategy.

Further to the knowledge and implications that surround a CRM, one of the main problems is that no model exists to guide companies in the implementation of this type of strategy. Each company is different and has its own culture and business processes. Consequently, it is important not to consider CRM as a magical solution that will solve all the company's problems. On the contrary, it must be studied to know its benefits and impacts for the organization. The implementation of this strategy requires hard work to be successful.

When managing the transition to a customer-centric organization, it is mandatory to develop the capabilities to acquire the necessary resources, knowledge, and tools to meet customer's requirements with the appropriate products and services. Unfortunately, many organizations, especially financial ones, have a product-oriented culture which could be inconsistent with the customer's expectations.

These organizations tend to set the processes in terms of the product lines instead of the customer lines. Furthermore, these companies have a legacy of customers who often become unprofitable and they lack the ability to properly develop strategies to meet the services required by the entire customer base (Mendoz, Marius, Perez, \& Griman, 2007).

CRM includes all the facilities of a company such as defining, getting, developing, and retaining loyal and profitable customers increasingly with regard to right product or service to the right customer with right price from right way on right time. CRM integrates sales, marketing, service, enterprise, resource planning, and supply chain management functions in order to maximise each customer relationship with company process automation, technological solutions, and information resources. It regulates relationship among entrepreneurs, customers, business partners, salers, and employers (Uysal \& Aksoy, 2004).

Croteau and $\mathrm{Li}$ (2003) defined CRM as a technological initiative and suggested three main organizational functions to be supported within the technological initiatives' landscape of CRM: customer support and service, sales force automation, and enterprise marketing automation.

Roberts, Liu, and Hazard (2005) recommended a general CRM flow below as searching CRM literature:

- developing customer strategy;

- setting customer objectives;

- assessing organizational readiness;

- aligning organization behind goals;

- executing CRM programs;

- measuring program effectiveness.

\section{Literature Review}

Academics and practitioners have tried to find the drivers of CRM success or failure with their own perspectives for many years. While some researches focused more on IT related factors, others emphasized 
organizational factors like human resources, organizational structures, and reward systems or business process-related factors (H. S. Kim \& Y. G. Kim, 2007).

One of the most important elements in CRM is human factor. Success with CRM strategy is related to supporting this strategy by people within the company (Uysal \& Aksoy, 2004).

A CRM business strategy includes marketing, operations, sales, customer service, human resources, R\&D and finance, as well as information technology and the internet to maximize the profitability of customer interactions. For customers, CRM offers customization, simplicity, and convenience for completing transactions, regardless of the channel used for interaction. To achieve the CRM objective, there is a series of aspects involved. The processes, human factor, and technology aspects for CRM are described in detail below (Mendoza et al., 2007):

(1) processes: CRM is a strategy within the organization that aims to satisfy and create a long-term relationship with the client. As such, one crucial factor of it is to analyze those processes which in any way involve interaction with the client. One must remember that depending on the type of business, the processes vary. Nevertheless, the main processes that involve client interaction are: marketing, sales, and services.

(2) human factor: The key factor in a CRM strategy is how the relationship with the client is handled. This approach relies on the fact that for this relationship to exist, there must be at least two parties involved: a provider and a buyer.

In order to have a stable relationship with the client, the company must be aware of three key aspects. First, it must know how the client defines value. Then, it must provide satisfaction according to the needs and value standards of the client. Finally, it must work toward retention and loyalty from the customer.

In a CRM strategy, it is vital that all levels of the organization be aligned toward favoring the relationship with the client, taking into account all of the implications of this objective. There are several aspects related to the organizational behavior, as indicated following:

- the change in culture within the company staff. Switching from a product-oriented approach to a client-oriented approach requires a change in attitude within the organization;

- the role played by the employee in successfully establishing a relationship with the customer, and in turn, generating customer loyalty, as well as profit. Therefore, employee retention becomes just as important as client retention. The longer the employee feels motivated and satisfied, the higher the commitment level to the company;

- at the managerial level, one aspect of great importance: the degree of commitment and participation on the part of those in high management positions.

In addition to the aspects already mentioned, it points out other general aspects to consider regarding organization: managing change, communication, follow-up, feedback, and effective leadership.

(3) technology: Main factors of technology including are information systems (IS), software for CRM, sales force automation (SFA), data warehouse, and data mining, help desk, internet influence, and call centers, coordinating the CRM implementation.

Croteau and Li's study (2003) indicates that CRM technological initiatives are successful, when adequate top management support and accurate knowledge management capabilities are supported by a suitable information technology infrastructure.

According to Forsyth's study (2001) with 700 company regarding factors on CRM's unsuccessful results, these factors have such a distribution: organizational change (29\%), company policies (22\%), not good 
understanding of CRM (20\%), and weak CRM capabilities (6\%).

Forsyth's findings are supported by Kirby's below added items (2001):

- not using all resources in order to get all information concerning customer as thinking that the customer is already known;

- ignoring system integration and organizational culture importance and believing that just a CRM software package is enough;

- inefficient communication between departments included in process;

- lack of metrics which are capable of measuring and understanding CRM's benefits and changes within the company.

According to Esteves and Pastor (2001), critical success factors provide competitive behavior for the company and affect the results. On this context, if a factor guarantees CRM application success, then this factor is defined as critical.

Each critical success factor has direct or indirect effect on CRM strategy's basic elements which are process, people, and technology. CRM is a process, people, and technology combination that aims to understand a company's customer base. Hence, managing of a successful CRM application needs a balanced approach integrated to process, people, and technology.

According to Zablah et al. (2004), CRM has five perspectives as process, strategy, philosophy, capability, and technology in order to get successful results:

- Process: CRM success is contingent upon a firm's ability to detect and respond to evolving customer needs and preferences;

- Strategy: CRM success requires that firms continually assess and prioritize customer relationships based on their relative lifetime profitability;

- Philosophy: CRM success requires that firms be customer-centric and driven by an understanding of customers' changing needs;

- Capability: CRM success is contingent upon a firm's possession of a set of tangible and intangible resources that afford it the flexibility to change its behavior towards individual customers on an ongoing basis;

- Technology: CRM success is primarily driven by the functionality and user acceptance of the technology that firms implement in an attempt to build customer knowledge and manage interactions.

Knowledge and interaction management are posited as the major sub-processes of the CRM macro level process. Knowledge management then refers to the organizational process that is concerned with the creation, storage, retrieval, and application of knowledge. Interaction management includes core benefits exchange, information exchange, and social exchange in which the buyer and seller engage in. Interaction quality is determined by the collective consistency, relevancy, and appropriateness of individual exchange episodes.

Zablah et al. (2004) outlined a basic framework that identifies the key steps towards CRM success. CRM success is defined hereafter as a firm's ability to efficiently build and sustain a profit-maximizing portfolio of customer relationships.

Ocker and Mudambi (2003) divided a company's CRM structure to three dimensions as intellectual, social, and technological. Their research is based on companies' CRM capability and what kinds of changes needed before a CRM initiative.

The intellectual dimension includes the categories of strategy, structure, and planning. Similarly, the social dimension includes the categories of culture, stakeholder interactions, and domain knowledge. Finally, the 
technological dimension consists of the CRM application, IT capability, and knowledge management categories.

(1) Intellectual dimension is described as follows:

- strategy: CRM initiative should be conceived of as a corporate strategy. The customer-related capabilities of a firm are at the heart of assumptions regarding customer satisfaction, productivity, and the firm's financial performance. According to marketing theory, in order to be successful, an organization must aim all of its efforts at satisfying its customers, at a profit that is, managing customer needs profitably. This means that organizations must create, deliver, and communicate customer value more effectively than their competitors. Organizations are successfully named as market driven, customer-centric, customer-focused, or customer-oriented;

- structure: The innovation literature suggests that a firm with a flat, decentralized structure, as opposed to a centralized hierarchical structure, is most likely to support the development of innovative ideas;

- planning: Planning can be defined as the state to which a high quality set of connected plans exists, involving corporate, business units, and IT.

(2) Social dimension is described as follows:

- culture: The culture of a firm is undoubtedly central in determining its readiness to undertake a CRM initiative. It is interpreted as organizational culture from one of three perspectives: integrated, differentiated, or fragmented. Organizational theory suggests that to the degree a firm's culture is integrated and aligned with its strategic objectives, goals, and expected outcomes, the culture will positively impact overall organizational performance;

- stakeholder interactions: A stakeholder is any group or individual who can affect or is affected by the achievement of the organization's objectives. A firm is conceptualized as a nexus of contracts, with top managers serving as contracting agents who engage in relationship management with stakeholders;

- domain knowledge: In the CRM context, shared domain knowledge refers to the knowledge that customer facing business unit share with respect to one another's business missions, objectives, and plans, as well as their global understanding of the firm.

(3) Technological dimension is described as follows:

- CRM application: The commercial development of CRM software, following on the heels of large-scale ERP systems, drives and enables CRM as a business strategy. Third-party CRM software packages offer a comprehensive set of technologies for managing the relationships with potential and current customers and business partners across marketing, sales, and customer service, regardless of the communication channel;

- IT capability: Research indicates that a balanced team composed of experts from business units and IT, as well as third party experts such as that consultants and vendors are critical;

- knowledge management: A key asset and resource of an organization is the knowledge it possesses. Knowledge management is the process of managing (e.g., capturing, representing, and making available) the intelligence and expertise resident in an organization. Companies need to explore and refine CRM knowledge management methods in order to get value added knowledge for themselves and their customers.

\section{Conceptual Framework and Research Model}

Main purpose of this study is to find out that how CRM critical factors affect the company performance. This paper focuses on relationship between critical success factors of CRM and company performance and then develops the research hypotheses. The research model is presented in Figure 1. 


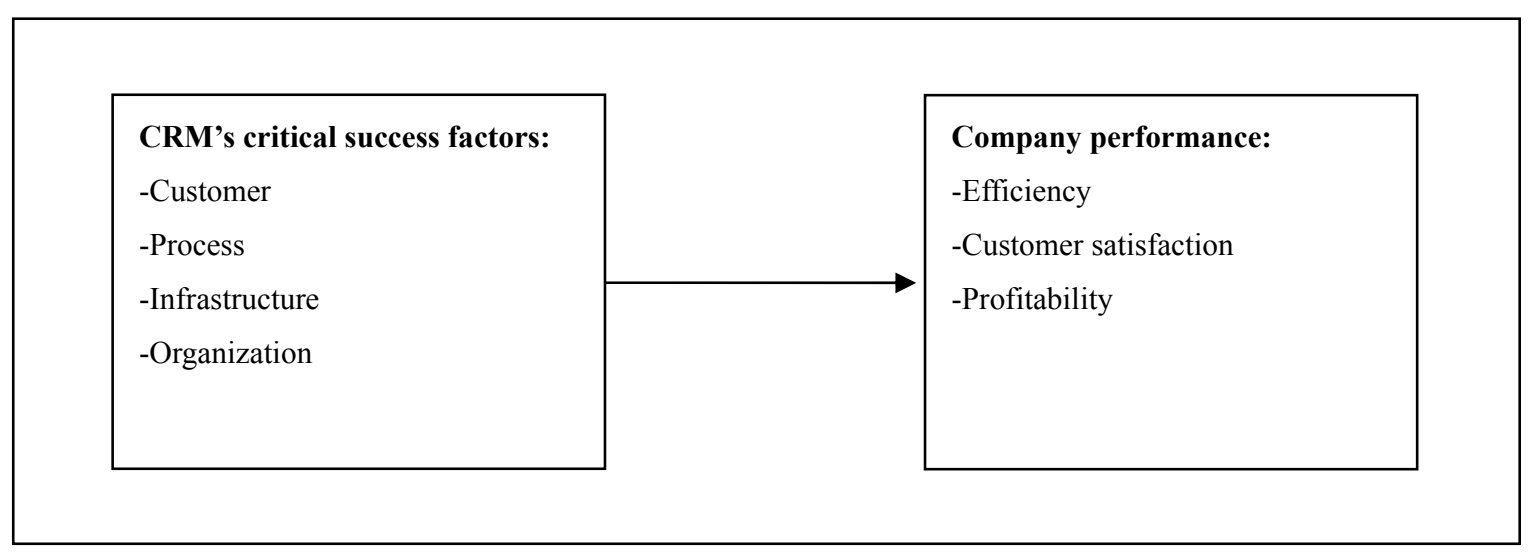

Figure 1. A model proposal CSFs effects for a successful CRM application.

According to above model CRM, critical success factors include customer, process, infrastructure, and organization as independent variables. Customer satisfaction, efficiency, and profitability which represent company performance are dependent variables. In order to show relationship between CRM's CFS and company performance results below, main hypothesis is defined:

H: CRM critical success factors are positively linked to company performance results.

\section{Research Methodology}

In this study, the effect of CRM's critical success factors (independent variables) on company performance (dependent variables) based on data collected from automotive sales agents in Turkey was analyzed. Basically, two main studies (H. S. Kim \& Y. G. Kim, 2007; Roh, Ahn, \& Han, 2005) were used to design the survey for the sales agents. It consisted of 54 items, scored on a 5-point Likert scale with an agree/disagree continuum ( $1=$ strongly disagree, $2=$ disagree, $3=$ neither agree nor disagree, $4=$ agree, and 5 $=$ strongly agree). The survey is sent by e-mail method to sales agents of main automotive groups which have sales activity in Turkey. In total 138 of surveys, 60 sales agents answered and sent back. The response rate is $43 \%$.

\section{Definition and Measurement of Variables}

CRM has been increasingly adopted by corporations as a core IT driven business strategy and firms have started to invest heavily in CRM. Academics and practitioners have tried to find the drivers of CRM success or failure with their own perspectives for many years. While some researches focused more on IT related factors, others emphasized organizational factors like human resources, organizational structures and reward systems, or business process-related factors.

However, though these partial studies have their own managerial implication, they are not appropriate for investigating the causes of CRM success or failure from an integrative perspective.

H. S. Kim and Y. G. Kim proposed a framework of CRM performance measurement, called CRM scorecard, which can diagnose and assess companies' CRM initiatives.

CRM scorecard framework includes customer, process, infrastructure, and organizational perspectives:

(1) Customer related factors are described as follows:

- defining customers which are value added for the company;

- defining target customers for the company; 
- defining resources to be allocated on customer basis;

- defining customer value of products and services;

- defining customer expectations;

- controlling current business processes and customer interaction ways efficiency.

(2) Process related factors are described as follows:

- constructing all process such as production, sales and aftersales customer oriented;

- defining measurable criteria for sustainable development;

- defining all processes and its details.

(3) Infrastructure related factors are described as follows:

- implementing knowledge sharing system not only for the customers but also through the corporation;

- making required CRM system infrastructure investments;

- IT strategies should support business strategies;

- active usage of CRM system.

(4) Organization related factors are described as follows:

- employing people who will empower the company and speed up change process;

- empowering and educating staff as a strategic priority;

- support and participation of top management;

- organizational loyalty and corporate culture;

- structuring a qualified CRM team.

With an ever-increasing competition for marketing dominance, many firms have utilized the CRM system for improved business intelligence, better decision making, enhanced customer relations, and good quality of services and product offerings.

Roh et al. (2005) analyzed factors which affect CRM success and divided these factors as intrinsic and extrinsic factors. Intrinsic success factors are defined as efficiency and customer satisfaction and extrinsic success factor as profitability. They measured internal efficiency as one of the intrinsic measures of CRM implementation success in terms of perceived improvements such as easiness of CRM, cost reduction, time saving, and alleviation of CRM load. Customer satisfaction was measured as an intrinsic CRM success by perceived level of the shift after CRM system implementation: friendly interaction with customer, brand value, customer complains, and overall customer satisfaction. The operationalized scales of profitability, as only extrinsic factor, include increase of new customers, reselling or upselling, decrease of customers' churn, and increase of overall profitability.

Organizations pursue a CRM strategy for the purpose of increasing business performance and value. However, firms face a multitude of organizational challenges associated with this endeavor. To reduce their risk of failure, it was suggested that firms undertake a deep analysis of organizational readiness prior to committing to a CRM initiative (Ocker \& Mudambi, 2003):

(1) Efficiency related factors are described as follows:

- making easy of CRM;

- less workload for CRM usage;

- cost decrease for CRM usage;

- time saving for CRM usage. 
(2) Customer satisfaction related factors are described as follows:

- satisfaction of customer from company's products and services;

- decreasing of customer complaints;

- increasing good interactions with customers.

(3) Profitability related factors are described as follows:

- cost saving;

- turnover increase through new customers or more sales to current customers;

- customer loss decrease;

- brand value increase.

\section{Statistical Analysis}

In order to find relationship among variables, correlation analysis was used. Also to see how independent variable dimensions affect dependent variable, regression analysis was performed.

The SPSS releases 16.0 software package was used for data analysis in the study. The value of Cronbach's $\alpha$ is adopted to examine reliability of all factors. Cronbach's $\alpha$ values are 0.902 for customer related factors, 0.917 for process related factors, 0.914 for infrastructure related factors, 0.931 for organization related factors, 0.954 for customer satisfaction related factors, 0.938 for profitability related factors, 0.947 for efficiency related factors, and 0.977 for all items.

In order to find out relationship and internal consistency of dependent and independent factors, a correlation analysis was performed, according to Pearson correlation coefficient. According to correlation analysis results, all critical success factors have positive relationship with company performance factors. Most powerful relationship is found among customer related factors with customer satisfaction (0.847) and efficiency (0.897). Also organization related factors have fairly powerful relationship with profitability $(0.619)$.

To explore the effects of the customer, process, infrastructure, and organization related factors on company performance dimensions as profitability, customer satisfaction, and efficiency, regression analysis was used. The results of analysis show that customer related factors explain $59 \%$ of customer satisfaction and $37 \%$ of efficiency. On the other hand, organization related factors explain $66 \%$ of profitability.

\section{Conclusions}

On one hand, main hypothesis of this study "CRM critical success factors are positively linked to company performance results" is supported, according to correlation analysis results. Some of the factors have relatively more powerful positive relationship than the others with company performance result items. However, all of them have positive relationship.

On the other hand, according to regression analysis results, it is found that customer and organization related factors have much more effects on company performance rather than infrastructure and process related factors. It can be said that according to this study's results, companies need to give more attention to customer and organization related factors, when they are applying CRM initiative in order to get positive results of company performance.

\section{References}

Croteau, A. M., \& Li, P. (2003). Critical success factors of CRM technological initiatives. Canadian Journal of Administrative Sciences, 20, 21-34. 
Esteves, J., \& Pastor, J. (2001). Analysis of critical success factors relevance along SAP implementation phases. Proceedings from the 7th Americas Conference on Information Systems.

Forsyth, R. (2001). Six major impediments to change and how to overcome them in CRM. Retrieved from $\mathrm{http} / /$ www.mycustomer.com/topic/technology/six-major-impediments-change-and-how-overcome-them-crm-and-politics

Kim, H. S., \& Kim, Y. G. (2007). A study on developing CRM scorecard. Proceedings from the 40th Annual Hawaii International Conference on System Sciences.

Kirby, J. (2001). CRM program management: The art of change, in presentations of conference on making the vision a reality. Paris: Gartner Group.

Mendoza, L. E., Marius, A., Perez, M., \& Griman, A. C. (2007). Critical success factors for a customer relationship management strategy. Information and Software Technology, 49, 913-945.

Ocker, R. J., \& Mudambi, D. S. (2003). Assessing the readiness of firms for CRM: A literature review and research model. Proceedings from the 36th Hawaii International Conference on System Sciences.

Roberts, M. L., Liu, R. R., \& Hazard, K. (2005). Strategy, technology, and organisational alignment: Key components of CRM success. Database Marketing \& Customer Strategy Management, 12, 315-326.

Roh, T. H., Ahn, C. K., \& Han, I. (2005). The priority factor model for customer relationship management system success. Expert Systems with Applications, 28, 641-654.

Uysal, F., \& Aksoy, Ş. (2004). Müşteri ilişkileri yönetimindeki temel boyutlar ve tıbbi malzeme lojistiği üzerine bir uygulama (Basic dimensions on customer relationship management and an application to medical material logistics). Akdeniz I.I.I.B.F. Dergisi, 7, 129-144.

Zablah, A. R., Bellenger, D. L., \& Johnston, W. J. (2004). An evaluation of divergent perspectives on customer relationship management: Towards a common understanding of an emerging phenomenon. Industrial Marketing Management, 33 , 475-489. 